\title{
A PERCEPÇÃO DOS ALUNOS SOBRE O USO DE MÍDIAS SOCIAIS NAS DISCIPLINAS DE ANATOMIA E HISTOLOGIA VETERINÁRIA
}

\author{
Valcinir Aloisio Scalla Vulcani ${ }^{1}$, Diego Pereira de Araújo ${ }^{2}$, Lucas José Santos \\ Mascarenhas ${ }^{3}$, Vanessa Sobue Franzo ${ }^{5}$, Cleomar Rocha ${ }^{5}$ \\ ${ }^{1}$ Professor Doutor - Coordenação de Medicina Veterinária - UFJ, Jataí-GO, Brasil \\ ${ }^{2}$ Mestre em Biociência Animal pela UFJ, Jataí-GO, Brasil. \\ ${ }^{3}$ Bacharel em Medicina Veterinária pela UFG-Regional Jataí, Jataí-GO, Brasil \\ E-mail: diegoaraujomv@outlook.com \\ ${ }^{4}$ Professora Doutora - Departamento de Zootecnia e Extensão Rural - UFMT, \\ Cuiabá, MT, Brasil \\ ${ }^{5}$ Professor Doutor - Faculdade de Artes Visuais - UFG, Goiânia-Go, Brasil
}

\section{Recebido em: 15/05/2020 - Aprovado em: 15/06/2020 - Publicado em: 30/06/2020}

DOI: 10.18677/EnciBio_2020B2

\begin{abstract}
RESUMO
A pesquisa foi realizada com os estudantes do curso de Medicina Veterinária das disciplinas de Histologia I e II e Anatomia I e II da Universidade Federal de Goiás Regional Jataí (Atual, Universidade Federal de Jataí/UFJ) com objetivo de avaliar, através de um questionário, a percepção dos alunos em relação a duas novas plataformas de estudos e o impacto que o uso dessas tiveram em seu aprendizado. Para tal, foi criado um website e um perfil na rede social 'facebook.com" que eram alimentados com materiais que pudessem dar suporte ao conteúdo apresentado em aula tais como informes, apostilas, postagens de textos relacionados ao conteúdo dado em aula, imagens anatômicas e histológicas; e vídeos trazendo explicações sobre assuntos relacionados a anatomia, histologia e até de comportamento e fisiologia animal. Ao fim do semestre os alunos responderam a um questionário com perguntas para avaliar quatro assuntos específicos: 1) opinião dos estudantes sobre a eficiência do método; 2) a satisfação com o uso dos métodos; 3) preferência por intensificação ou redução dos métodos e 4) opinião dos alunos se esse sistema deveria incluir outras ferramentas de mídia conectadas. A análise dos questionários mostraram que a utilização das mídias nas disciplinas de anatomia e histologia veterinária de forma complementar, despertou o interesse dos estudantes, favorecendo o contato com materiais didáticos e incentivando o estudo.
\end{abstract}

PALAVRAS-CHAVE: Anatomia, Histologia, mídias sociais.

\section{THE STUDENTS' PERCEPTION ON THE USE OF SOCIAL MEDIA IN THE SUBJECTS OF ANATOMY AND HISTOLOGY VETERINARIA}

\begin{abstract}
The research was carried out with students of the Veterinary Medicine course of the disciplines of Histology I and II and Anatomy I and II of the Federal University of Goiás - Regional Jataí (Current, Federal University of Jataí / UFJ) with the objective of evaluating, through a questionnaire, students' perception of two new study
\end{abstract}


platforms and the impact that their use had on their learning. To this end, a website and a profile on the social network "facebook.com" were created, which were fed with materials that could support the content presented in class such as reports, handouts, text posts related to the content given in class, anatomical images and histological; and videos bringing explanations on subjects related to anatomy, histology and even animal behavior and physiology. At the end of the semester, students answered a questionnaire with questions to evaluate four specific subjects: 1) students' opinion about the efficiency of the method; 2) satisfaction with the use of methods; 3) preference for intensifying or reducing the methods and 4) students' opinion whether this system should include other connected media tools. The analysis of the questionnaires showed that the use of the media in the disciplines of anatomy and veterinary histology in a complementary way, aroused the interest of the students, favoring the contact with didactic materials and encouraging the study.

KEYWORDS: Anatomy, histology, social media

\section{INTRODUÇÃO}

A entrada de novas tecnologias em salas de aula facilita a criação de projetos educacionais, intercâmbios interpessoais e a comunicação à distância de tal forma que essas atividades vão redefinindo a relação estabelecida entre professor e aluno (VALENTE, 2014; ZUINS, 2016). Os professores já não são mais vistos como líderes oniscientes e os materiais de ensino estão evoluindo de livros didáticos para programas computacionais e projetos mais amplos o que torna as informações mais acessíveis, com os usuários escolhendo o que querem aprender e com todos possuindo a chance de tornarem-se criadores de conteúdo (LIBÂNEO, 2013).

Neste contexto, as mídias sociais são recursos on-line para interação social com a capacidade de disseminar conteúdo, compartilhar opiniões, conceitos, ideias, experiências e perspectivas em uma abordagem colaborativa (LÉVY, 1999; SCHNEIDER; SOUZA, 2014).

O ensino de histologia é baseado tradicionalmente em palestras e aulas de laboratório, utilizando microscópios ópticos que fazem com que os alunos vivenciem passivamente o processo de ensino-aprendizagem (BUTTOW; CANCINO, 2007; HORTSCH, 2013). Ceccantini (2006), ressalta que as dificuldades encontradas pelos alunos em obter diagnósticos em histologia vegetal e animal se originam principalmente do fato da análise dessas imagens se dar em duas dimensões sendo que, em verdade, essas se estruturam em três dimensões devendo o aluno se esforçar para ter uma boa capacidade de abstração. Dificuldades em identificar e memorizar as estruturas observadas assim como a manipulação do microscópico também estão presentes (SANTA-ROSA; STRUCHINER, 2011).

$\mathrm{Da}$ mesma forma, as disciplinas de anatomia também podem trazer dificuldades para os alunos entenderem as aplicações práticas do conteúdo ensinado (REIS et al., 2013). Historicamente, a anatomia é ensinada em aulas teóricas e práticas, como estudo das amostras anatômicas preparadas e a dissecação de cadáveres. Entretanto, essa abordagem clássica tem sido questionada por metodologias mais didáticas em abordar o conteúdo, principalmente nas aulas práticas onde os alunos começam a ser mais protagonistas no processo de aprendizagem e não mais exclusivamente dependentes da exposição de peças por parte de um professor (BRAZ, 2009).

As "Tecnologias de Informação e Comunicação" - (TICs) oferecem um campo fértil para a exploração na busca pela consolidação de currículos mais flexíveis, adaptados às características de aprendizagem dos estudantes e permitindo maior 
independência e autonomia em sua formação acadêmica (DUTA; MARTíEZRIVERA, 2015; NOBREGA et al., 2018). Os chamados "Ambientes Virtuais de Aprendizagem" - (AVAs) permitem não só maior disponibilidade e acessibilidade a conteúdos audiovisuais, mas também podem enriquecer a criação e reprodução de simulações tornando-as mais reais e incluindo até mesmo aspectos culturais, emocionais e comunicativos em um contexto que sempre tenta ligar o aluno a prática profissional (VACONCELOS; VASCONCELOS, 2013).

As redes sociais, tais como o "Facebook.com", também podem ser usadas como ferramentas didáticas para auxiliar nos estudos e aproximar professores e alunos pois são amplamente utilizadas, conseguem suportar diferentes formas de criar e passar informações além de facilitar a comunicação (REIS et al., 2013; SCHERER; FARIAS, 2018).

Este estudo teve como objetivo desenvolver duas plataformas de mídias sociais para complementar o conteúdo das disciplinas de anatomia e histologia veterinária e avaliar a percepção dos estudantes participantes sobre o material e o impacto na aprendizagem.

Criação do site original

\section{MATERIAIS E MÉTODOS}

Para a realização do projeto foram selecionados alunos do curso de Medicina Veterinária da Universidade Federal de Goiás, Regional Jataí (Atualmente, Universidade Federal de Jataí/UFJ) que iriam cursar as disciplinas Anatomia Veterinária I, Anatomia Veterinária II, Histologia Veterinária I e Histologia Veterinária II nos anos de 2015 e 2016. No total, foram convidados 150 alunos, dos quais 125 responderam. Para todos os alunos os conteúdos foram administrados utilizando-se os meios convencionais de aulas teóricas e práticas, porém, foi proposta a complementação com materiais didáticos postados em mídias sociais. Os alunos foram instruídos a acessar o conteúdo e realizar tarefas pelas plataformas digitais. Para isso foi desenvolvido um website em "HTML", hospedado no Plataforma do Blogger com domínio ".com".

Em seguida, foram definidos os aspectos estéticos do local, levando em consideração a necessidade de utilizar fotografias de instalações físicas e partes anatômicas. As cores utilizadas foram azul e branco, alinhadas com as cores do símbolo da Universidade Federal de Goiás (Figura 1).

FIGURA 1. Aparência estética original do site do laboratório de anatomia animal (LAAN).

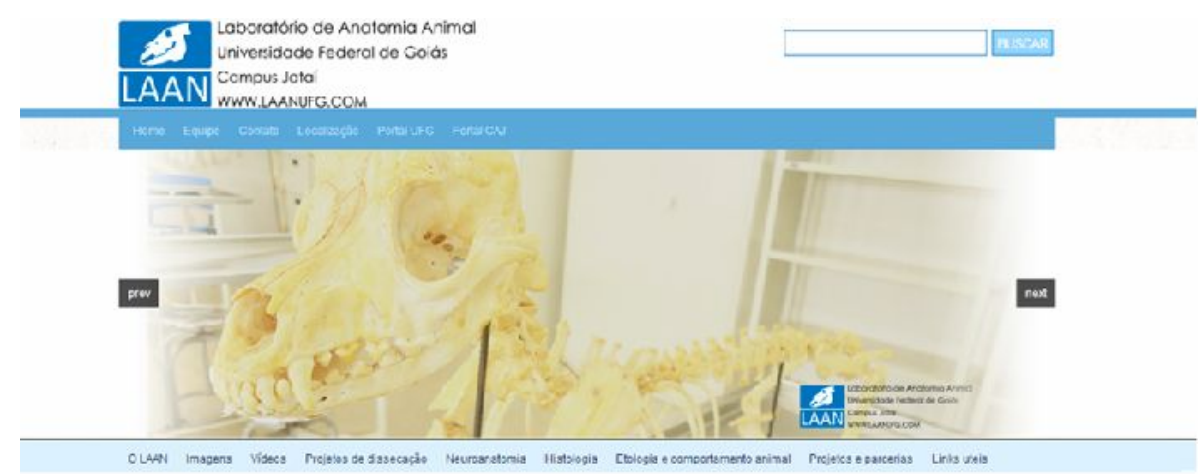


Uma vez criada a página, foram distribuídos os ícones no menu superior da seguinte forma: Home, Equipe, Contato, Localização, Portal UFG, Portais CAJ. Os ícones do menu inferiores estavam distribuídos como: O LAAN (Laboratório de Anatomia Animal), imagens, vídeos, projetos de dissecação, neuroanatomia, histologia, etologia e comportamento animal; projetos e parcerias; e outros links úteis.

Após a preparação da página, foram inseridos conteúdos relacionados à anatomia, histologia assim como outros assuntos relacionados às atividades laboratoriais, como fisiologia e comportamento animal. Foram produzidos vídeos de 15 minutos com conteúdo de aulas práticas, utilizando uma câmera digital prosumer e editados para serem assistidos na web.

Ao mesmo tempo, uma página no "Facebook" foi criada com a mesma identidade visual e cor, para postagens semanais e informações de atividades de laboratório. As postagens, em grande maioria, exibiam curiosidades de anatomia, histologia e questões relacionadas aos animais (Figura 2).

FIGURA 2. Aparência visual da página do Facebook para o Laboratório de Anatomia Animal

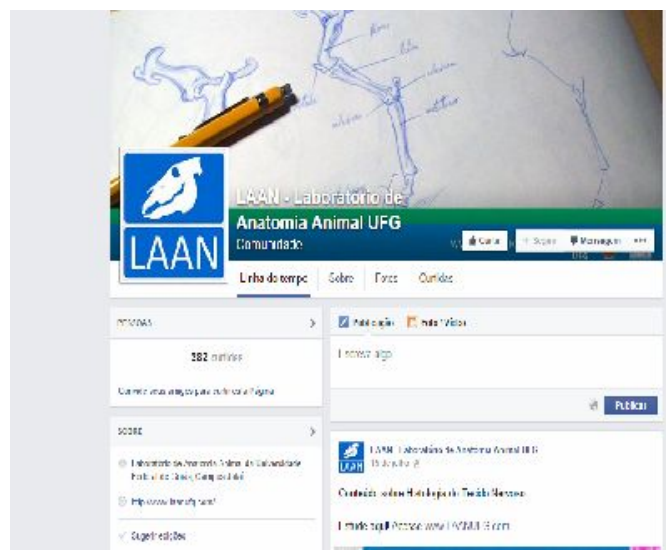

Disponível em https://www.facebook.com/laanufg.

Análise técnica e revisão de website

O site "laanufg.com" passou por avaliação técnica, conforme determinado no projeto, para ser revisado em estética, acessibilidade e, também para se adequar as normas da lei federal relativa ao desenvolvimento de websites e uso no ensino superior. A primeira revisão culminou com a migração para o domínio da Universidade Federal de Goiás. Para tanto, foi criada uma nova página, mantendo a denominação do laboratório de anatomia animal, com o acrônimo "LAAN" e o novo endereço www.laan.ufg.jatai.br (Figura 3). No entanto, para que o acesso ao endereço antigo www.laanufg.com não prejudicasse os participantes do projeto e os usuários em geral, foi criado um redirecionamento para o novo domínio. Após a página estar ativa e sendo acessada, foi solicitada uma análise e assessoria técnica por meio de avaliação heurística e testes de usabilidade. 
FIGURA 3. Aspecto visual do site do Laboratório de Anatomia Animal no modelo adotado pela Universidade Federal de Goiás

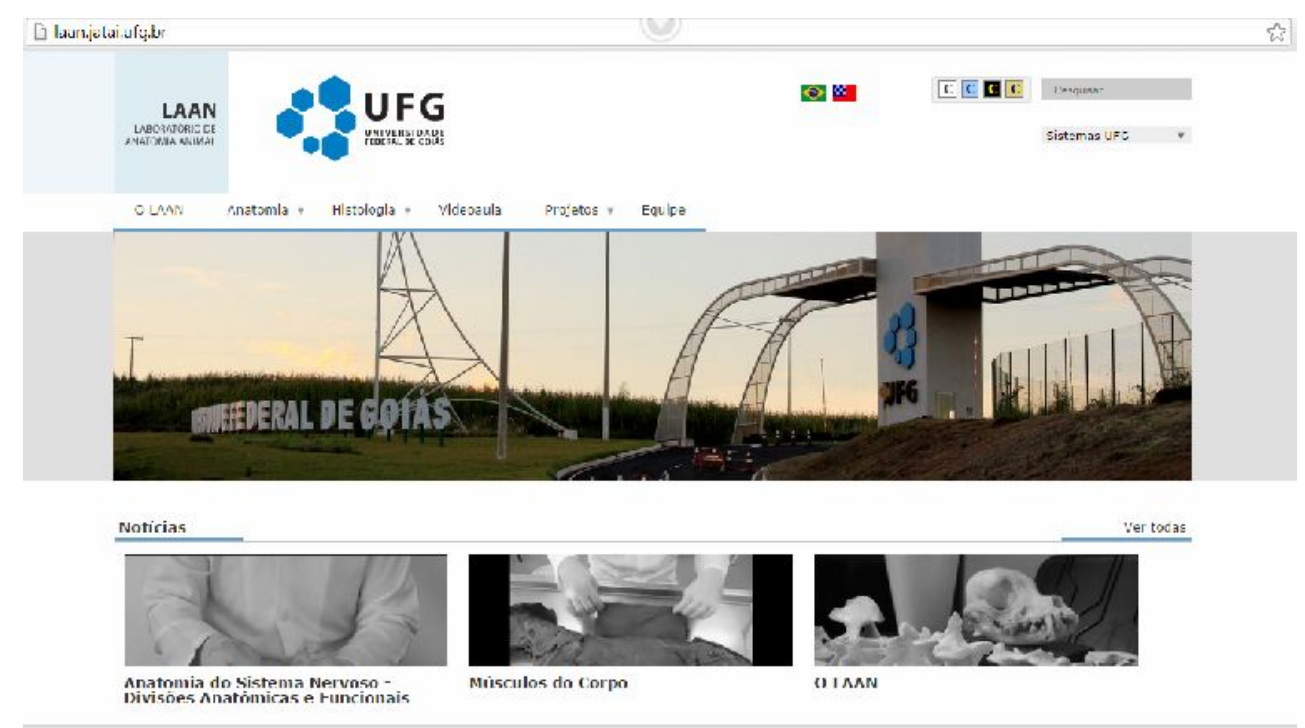

. Disponível em http://laan.jatai.ufg.br.

Coleta dos dados sobre a percepção dos alunos participantes

Ao fim do semestre, os alunos foram inqueridos por meio de um questionário sobre o método utilizado, com o objetivo de coletar informações e avaliar a efetividade ou os principais impactos na aprendizagem das disciplinas escolhidas. A participação foi voluntária, sem identificação e realizada somente após 0 preenchimento dos Termos de Consentimento.

O termo de consentimento foi lido e explicado pelo coordenador da pesquisa que esclareceu que o questionário seria utilizado para o projeto, sem influência nas notas das disciplinas e que o participante poderia ser desistir a qualquer momento da pesquisa, se preferisse. O projeto foi registrado na plataforma do Brasil para ser avaliado pelo comitê de ética e foi aprovado sob o protocolo 567.647.

O questionário incluiu quatro categorias com cada uma possuindo quatro questões de múltipla escolha (Quadro 1). Na primeira categoria, as questões avaliaram a opinião dos estudantes sobre a eficiência do método. Na segunda categoria, o foco estava na satisfação com o uso do método. A terceira avaliou se os alunos preferiam o método de intensificação ou redução. Na quarta categoria foi abordada a opinião dos alunos se esse sistema deveria incluir outras ferramentas de mídia conectadas.

Além das quatro categorias principais, o formulário tinha duas questões abertas para comentários. Os questionários contaram com a explicação: "Instruções: As questões têm números a serem marcados (de zero a cinco), sendo zero (0) o mínimo e cinco (5) o valor máximo que pode ser atribuído de acordo com as questões e sua opinião. Selecione apenas um número como resposta. " 
QUADRO 1. Modelo de questionário aplicado a estudantes que utilizaram as ferramentas de mídia nas disciplinas de anatomia e histologia veterinárias.

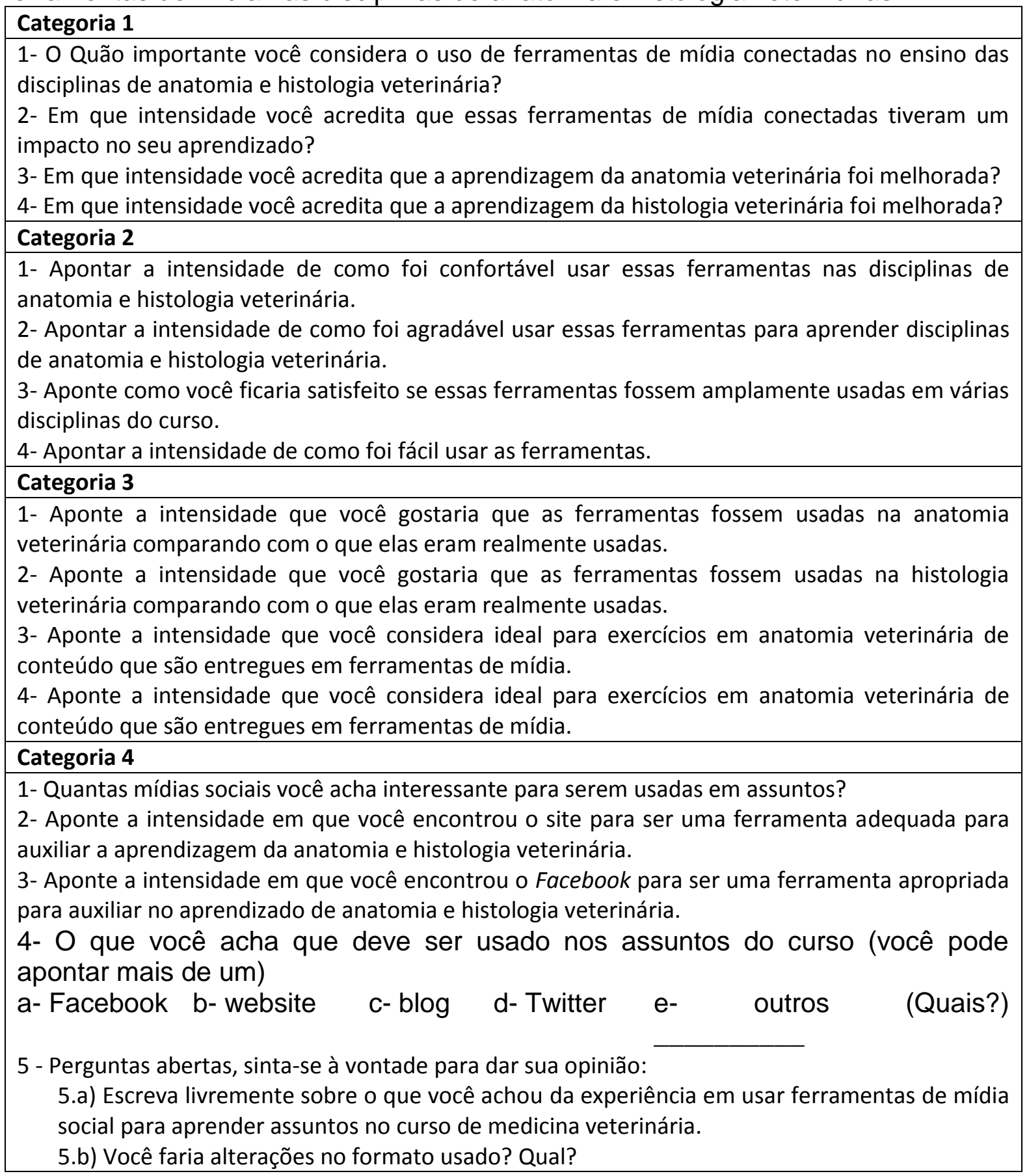

\section{RESULTADOS E DISCUSSÕES}

A Assessoria e análise técnica apontou que o site LAAN/UFG no mecanismo de busca do Google destacou-se como a quarta página no ranking e o perfil no Facebook estava na primeira posição em novembro de 2016, quando o projeto estava finalizado. Mediante esses resultados, foram feitas recomendações para produzir mais conteúdo para o site dentro dos critérios estabelecidos.

Em relação à análise da percepção dos estudantes sobre o método proposto e sua eficiência, os dados obtidos dos questionários revelaram aspectos importantes para o adequado alinhamento do uso das mídias sociais no ensino de anatomia e 
histologia veterinária. As respostas às questões do questionário estão compiladas na Tabela 1.

TABELA 1. Quantidades de respostas dos discentes no questionário de percepção sobre material e métodos utilizados no projeto de mídias sociais para complementação do processo ensino-aprendizagem das disciplinas de anatomia e histologia veterinária no ambiente universitário. Compilação por categorias e questões. Exposição em valores absolutos e frequências, em parênteses.

\begin{tabular}{|c|c|c|c|c|c|c|c|c|}
\hline \multicolumn{9}{|c|}{ Quantidade e frequência de respostas } \\
\hline Categoria & $\begin{array}{c}\text { Questão } \\
1\end{array}$ & 0 & \multirow{4}{*}{$\begin{array}{c}1(0,8) \\
2(1,68 \\
)\end{array}$} & 2 & $\begin{array}{c}\mathbf{3} \\
9(7,2)\end{array}$ & $\begin{array}{c}\mathbf{4} \\
25(20)\end{array}$ & $\begin{array}{c}\mathbf{5} \\
91(72,8)\end{array}$ & $\begin{array}{c}\text { Total } \\
125\end{array}$ \\
\hline \multirow{3}{*}{1} & 2 & \multirow{3}{*}{$2(1,68)$} & & $1(0,8)$ & $24(19,2)$ & $52(41,6)$ & $47(37,60)$ & 125 \\
\hline & 3 & & & $7(5,88)$ & $34(28,57)$ & $42(35,29)$ & $32(26,9)$ & 119 \\
\hline & 4 & & & $6(4,8)$ & $21(16,8)$ & $41(32,8)$ & $57(45,6)$ & 125 \\
\hline \multirow{4}{*}{2} & 1 & & & $1(0,97)$ & $19(18,45)$ & $25(24,27)$ & $58(56,31)$ & 103 \\
\hline & 2 & & & $1(0,81)$ & $21(17,07)$ & $46(37,40)$ & $55(44,72)$ & 123 \\
\hline & 3 & & & & $4(3,2)$ & $19(15,35)$ & $101(81,45$ & 124 \\
\hline & 4 & & & & $15(12)$ & $44(35,20)$ & $66(52,80)$ & 125 \\
\hline \multirow{4}{*}{3} & 1 & $2(1,61)$ & \multirow{4}{*}{$\begin{array}{c}2(1,61 \\
) \\
3(2,44 \\
) \\
1(0,81 \\
)\end{array}$} & $3(2,42)$ & $15(12,10)$ & $34(27,42)$ & $68(54,84)$ & 124 \\
\hline & 2 & $1(0,81)$ & & $6(4,87)$ & $12(9,76)$ & $29(23,58)$ & $72(58,54)$ & 123 \\
\hline & 3 & & & $1(0,81)$ & $20(16,13)$ & $45(36,29)$ & $57(45,96)$ & 124 \\
\hline & 4 & & & & $20(16,26)$ & $47(38,21)$ & $56(45,53)$ & 123 \\
\hline \multirow{4}{*}{4} & 1 & & $\begin{array}{c}5(4,10 \\
)\end{array}$ & $17(13,93)$ & $40(32,79)$ & $24(19,67)$ & $36(29,51)$ & 122 \\
\hline & 2 & & $3(2,44$ & $9(7,32)$ & $14(11,38)$ & $37(30,08)$ & $60(48,78)$ & 123 \\
\hline & 3 & $12(9,76)$ & $8(6,5)$ & $10(8,13)$ & $28(22,76)$ & $28(22,76)$ & $37(30,09)$ & 123 \\
\hline & $4^{*}$ & $\star *$ & 71 & 104 & 47 & 2 & $16^{\star * \star}$ & 240 \\
\hline
\end{tabular}

* Na pergunta "4" da categoria "4" os alunos podiam assinalar mais de uma resposta

** Questões sem opiniões foram contadas como zero.

*** Categoria chamada "outros (quais?)", com opção de sugestão aberta onde os alunos podiam escolher mais de uma opção. As seguintes respostas foram obtidas: youtube (4) gmail (1), aplicações (1), e-mail (2), whatsapp (2), vlog (1) video aulas (1), e "mais de uma".

Para a categoria "um", a pergunta 1: "O Quão importante você considera o uso de ferramentas de mídia conectadas para ensinar disciplinas de anatomia e histologia veterinária", e a 2 "Até que ponto você acredita que essas ferramentas de mídia interligadas impactaram seu aprendizado?" tiveram marcações predominando entre o grau 3 a 5 o que demonstra o interesse dos alunos em usar esses materiais e métodos. As redes sociais podem ter um impacto positivo no interesse do aluno em relação ao assunto proposto, o que pode melhorar o desempenho e melhorar as notas mesmo em temas considerados difíceis (ALMEIDA, 2016). A associação entre aulas e meios didáticos alternativos pode motivar os alunos, aumentar o interesse 
no conteúdo da disciplina e reforçar a relação entre alunos, professores e monitores (ANDRADE et al., 2020).

Ainda na categoria "um", os graus de intensidade 3, 4 e 5 também foram maiores nas questões três, referente a pergunta: ""Em que intensidade você acredita que a aprendizagem da anatomia veterinária foi melhorada?"; e a questão quatro, referente a pergunta: "Em que intensidade você acredita que a aprendizagem da histologia veterinária foi melhorada?". As respostas mostraram que há uma percepção estudantil de influência das redes sociais no melhor aprendizado nas duas disciplinas o que corrobora com outros trabalhos relacionados ao ensino das áreas biológica e de saúde (REIS et al., 2013) incluindo aqueles dentro da área de histologia (OLIVEIRA JUNIOR; SILVA, 2014)

$\mathrm{Na}$ categoria dois, a questão 1 " Apontar a intensidade de como foi confortável usar essas ferramentas nas disciplinas de anatomia e histologia veterinária." Houve um predomínio das intensidades três, quatro e cinco, o que pode significar que os métodos utilizados são de fato os mesmos que os alunos têm facilidade de manuseio, compreensão e acesso (MIRANDA et al., 2014), muito provavelmente pela familiridade que esses já tem com essas mídias (BAIRRAL, 2007).

$\mathrm{Na}$ questão dois da categoria dois, que buscou verificar a satisfação com o uso das ferramentas (Apontar a intensidade de como foi agradável usar essas ferramentas para aprender disciplinas de anatomia e histologia veterinária.), houve predomínio de intensidades de três a cinco que confirmou que o aluno se sente a vontade com esse sistema. Scherer e Farias, (2018), destacam o uso das mídias sociais, utilizando o "facebook.com" como ferramenta que pode ser usada para fins didáticos e que é familiar aos alunos.

A questão três "Aponte o quanto você ficaria satisfeito se essas ferramentas fossem amplamente utilizadas em várias disciplinas do curso" mostrou um predomínio de intensidades quatro e cinco, das quais $101(81,45 \%)$ marcavam em intensidade cinco. Isso mostra que são ferramentas que atendem às aspirações dos alunos além de poder ser usada para estimular iniciativas parecidas em outras disciplinas do curso. Na questão quatro, "apontar como foi fácil usar as ferramentas" predominaram as intensidades três, quatro e cinco, reafirmando que estes são recursos e materiais que os alunos têm intimidade ou facilidade de manuseio.

É preciso considerar que as novas gerações de alunos estão acostumados a receber informações por meios digitais e equipamentos de manipulação, como dispositivos móveis, o que pode permitir uma relação mais profunda com o material criado em plataformas digitais. Champangnatte e Nunes (2011), destacam a importância da mídia e do uso da internet no interesse do aluno e no processo de aprendizagem, explorando principalmente ferramentas audio-visuais.

$\mathrm{Na}$ categoria três, as questões um e dois pretendiam verificar se os alunos desejavam um uso mais intenso de materiais nas disciplinas de anatomia e histologia em comparação com o que era usado com as perguntas: " Aponte a intensidade que você gostaria que as ferramentas fossem usadas na anatomia veterinária comparando com o que elas eram realmente usadas" e "Aponte a intensidade que você gostaria que as ferramentas fossem usadas na histologia veterinária comparando com o que elas eram realmente usadas). Com a predominância das intensidades de três a cinco para ambas as respostas, percebeuse que é possível otimizar os materiais e métodos propostos para os alunos o que pode levar a formas de ensino ainda mais complexas usando as mídias sociais, assim como a distribuição de mais conteúdo por meio dessas plataformas. 
Costa et al. (2016) mostram que a disposição dos materiais didáticos pelo uso do facebook tem um importante papel no ensino e no aprendizado. O uso das redes sociais como ferramenta de aprendizado além de ser medido com a satisfação e percepção dos alunos também pode ser medido com o aumento das notas desses (ALMEIDA et al., 2017).

Nas perguntas 3 e 4 da categoria "três" há uma busca em verificar os desejos dos alunos para exercícios sobre os assuntos fornecidos em Anatomia e Histologia usando as mídias sociais. Essas perguntas foram respondidas predominantemente com respostas nas intensidade três a cinco. A dosagem dos exercicios por essas redes sociais e de mídia precisa se adequar à realidade do aluno e buscar formas de ensino e avaliações que sejam compatíveis com essa realidade (SILVA; SERAFIM, 2016) . O desejo dos estudantes de otimizar seus exercícios por meio das mídias sociais podem apontar uma opção a mais de avaliação a qual os professores podem optar por seguir.

Nesse aspecto, ficou clara a necessidade de criação e adaptação de reursos educacionais, buscando viabilizar uma nova forma de interação entre professores, alunos e currículo. Os alunos já estão familiarizados com as redes sociais e já sabem usar essas ferramentas, por isso é mais fácil explorar seus recursos (BAIRRAL, 2007). Portanto, é possível estender o espaço físico da sala de aula. Desta forma, os alunos não se limitam apenas ao tempo de uma aula e têm a oportunidade de expandir sua pesquisa sobre assuntos que realmente thes interessam. Assim, pode contribuir na redução das barreiras de comunicação entre alunos e professores (JULIANI et al., 2012; TORI, 2017).

Esse não é um processo que retira o papel e a importância do professor e nem mesmo que 0 isenta de suas obrigações didático e pedagógicas e sim que amplia suas ferramentas de ensino pois as novas ferramentas de tecnologia devem servir a prática pedagógica onde elas lhes cabem ser usadas. De acordo com Echalar et al. (2016) "(...) no processo de apropriação didático-pedagógica de tecnologias, os professores não podem ser considerados nem totalmente autônomos nem inteiramente submissos"

$\mathrm{Na}$ categoria quatro, a pergunta um "Quantas mídias sociais você acha interessante para ser usado em assuntos?", Houve um predomínio das respostas três, quatro e cinco, reafirmando novamente que as ferramentas são aceitas pelos alunos. Na questão dois "Aponte a intensidade em que você encontrou o site para ser uma ferramenta adequada para auxiliar a aprendizagem de anatomia e histologia veterinária" predominou as quatro e cinco intensidades, as quais também foram semelhantes às respostas para a questão três "Aponte a intensidade em que você encontrou Facebook ser uma ferramenta apropriada para auxiliar a aprendizagem da anatomia e histologia veterinária ".

A questão quatro "O que você acha que deve ser usado nas disciplinas do curso" demonstrou que houve predileção pelo uso do site, com 104 notas, seguido pelo Facebook, com 71 respostas; blog, com 47; Twitter, com 2; e "outros" com 16 sendo que nesses os alunos marcaram outros sites sendo os principais: Youtube (4), Gmail (1), aplicações (1), e-mail (2) Whatsapp (2), vlog (1) video class (1) e "todas as outras opções" (2).

$\mathrm{Na}$ última década, houve um aumento significativo nos recursos on-line, seja para entretenimento, relacionamento ou educação. Considerando a relação dos alunos com esses recursos, deve-se atentar para a otimização da aprendizagem por meio das ferramentas disponíveis. O Facebook pode ser explorado como uma importante ferramenta educacional, especialmente na promoção da elaboração do 
processo educacional, e ainda mais, permite a construção crítica e reflexiva da informação e do conhecimento (FERNANDES, 2011; ALLEGRETTI et al., 2012; HORTSCH, 2013; SCHERER; FARIAS, 2018).

\section{CONCLUSÃO}

A utilização das mídias sociais nas disciplinas de anatomia e histologia veterinária de forma complementar, despertou o interesse dos estudantes, favorecendo o contato com materiais didáticos específicos e incentivando diversas formas de estudo, atualizando métodos convencionais e conceitos de processos de ensino-aprendizagem. Além disso, havia a possibilidade de estudar, remotamente, conteúdos práticos que tradicionalmente só poderiam ser abordados no ensino de laboratórios e livros, o que facilitou e otimizou o processo de aprendizagem.

\section{REFERÊNCIAS}

ALLEGRETTI, S.M.M; HESSEL, A.M.G.; HARDAGH, C.C.; DA SILVA, J.E. Aprendizagem nas redes sociais virtuais: o potencial da conectividade em dois cenários. Revista Contemporaneidad educacion y tecnologia, v. 01, n. 02, p.5460 2012.

Disponível em: https://revistacontemporaneidadeeducacaoetecnologia02.files.wordpress.com/2012/ 04/pucsp_2012.pdf>

ALMEIDA, H.M. O uso de celulares, tablets e notebooks no ensino da matemática The use of cellphones, tablets e notebooks in the teaching of mathematics. REVEMAT, v. 11, p. 2, p. 318-287, 2016. doi: 10.5007/1981-1322.2016v11n2p318

ALMEIDA, C.M.M.; COSTA, R.D.A.; LOPES, P.T.C. Análise do desempenho acadêmico e da aprendizagem significativa no ensino superior utilizando as tecnologias digitais. Nuances: estudos sobre Educação. v. 28, n. 1, p. 25-43, 2017. doi: $10.14572 /$ nuances.v28i1.4836

ANDRADE, C.F.S.; SILVA, D.R.; PERUZZO, E.G.; VEIGA, M.L. O uso das tecnologias de informação e comunicação no ensino da disciplina de histologia. Brazilian Journal of Development, v. 6, n. 1, p. 3359-3362, 2020. doi: $10.34117 /$ bjdv6n1-242

BAIRRAL, M. A. Discurso, interação e aprendizagem matemática em ambientes virtuais a distância. Rio de Janeiro: Edur, 2007.

BOZARTH, J. Social Media for Trainers: Techniques for Enhancing and Extending Learning. San Francisco, CA: Pfeiffer, 2011.

BUTTOW, N.C. e CANCINO, M.E.C. Técnica histológica para a visualização do tecido conjuntivo voltado para os ensinos fundamental e médio. Arquivo do Mudi, v.11, n. 2, p. 36-40. 2007. Disponível em: < http://periodicos.uem.br/ojs/index.php/ArqMudi/article/view/20001/10840>

BRAZ, P.R.P. Método Didático Aplicado Ao Ensino Da Anatomia Humana. Anuário da Produção Acadêmica Docente, v. 3, n. 4, p. 303-310, 2009. Disponível em: < http://repositorio.pgsskroton.com/bitstream/123456789/1342/1/Artigo\%2020.pdf> 
CECCANTINI, G. Os tecidos vegetais têm três dimensões. Revista Brasileira de Botânica., V.29, n.2, p.335-337, abr.-jun. 2006. Disponível em: < http://www.scielo.br/pdf/rbb/v29n2/a15v29n2.pdf >

CHAMPANGNATTE, D.M.O.; NUNES, L.C. A inserção das mídias audiovisuais no contexto escolar. Educação em revista, v .27, n.3, p. 15-38, 2011. doi: $10.1590 /$ S0102-46982011000300002

COSTA, R.D.A.; ALMEIDA, C.M.M.; NASCIMENTO, J.M.M.; LOPES, P.T.C. Contribuições da utilização do facebook como ambiente virtual de aprendizagem de anatomia humana no ensino superior. Redin, v. 5, n. 1, 2016. Disponível em: < https://seer.faccat.br/index.php/redin/article/view/446 >.

DUTA, N.; MARTÍEZ-RIVERA, O. Between Theory and Practice: The Importance of ICT in Higher Education as a Tool for Collaborative Learning. Procedia - Social and Behavioral Sciences. v, 180, n. 5, p. 1466-1473, $2015 . \quad$ Doi: 10.1016/j.sbspro.2015.02.294

FERNANDES, L. Redes Sociais Online e Educação: Contributo do Facebook no Contexto das Comunidades Virtuais de Aprendentes, 2011. Disponível em: http://www.trmef.lfernandes.info/ensaio_TRMEF.pdf. Acesso realizado em: $30 / 08 / 2014$

HORTSCH, M. Virtual Biology: Teaching Histology in the Age of Facebook. The FASEB Journal, v. 27, n. 2, p. 411-413, 2013. Doi: 10.1096/fj.13-0201ufm

ECHALAR, A.D.L.F.; PEIXOTO, J.; CARVALHO, R.M.A. "A tecnologia não tem que ser maior do que o professor": visão dos professores quanto ao uso da tecnologia no contexto escolar. Revista educação e cultura contemporânea, v. 13, N. 31, p.160180, 2016. doi: 10.5935/2238-1279.20160027

OLIVEIRA JÚNIOR, J.K.; SILVA, M.A.D. As tecnologias de informação e comunicação como ferramenta complementar no ensino da histologia nos cursos odontologia da Região Norte. Jounal of health informatics, v. 6, n. 2, p.60-66, 2014. Disponível em: <http://www.jhi-sbis.saude.ws/ojs-jhi/index.php/jhisbis/article/view/293>

JULIANI, D.P.; JULIANI, J.P.; SOUZA, J.A.; BETTIO, R.W. Utilização das redes sociais na educação: guia para o uso do Facebook em uma instituição de ensino superior. Novas Tecnologias na Educação, v. 10, n. 13, 2012. doi: $10.22456 / 1679-1916.36434$

LÉVY, Pierre. Cibercultura. São Paulo: Editora 34, 1999.

LIBÂNEO, J.C. Adeus professor, Adeus professora? - Novas exigências educacionais e profissão docente. Ed.Cortez Editora, 13 ed., 2013.p. 104

MIRANDA, L.; MORAIS, C.; ALVES, P.; DIAS, P. Redes sociais na aprendizagem: motivação e utilização dos estudantes do ensino superior. In Moreira, J. António; Barros. D.; Monteiro, A. (orgs.) Educação a Distância e eLearning na Web Social. Santo Tirso: White Books. 1 ed. p. 73-95. 2014 
NOBREGA, T.E.; RIBEIRO, E.C.; OLIVEIRA JUNIOR, J.K..; PEREIRA, A.C.; SILVA, M.A.D. O uso das tic como ferramenta de ensino da histologia nos cursos de odontologia das regiões sul e sudeste do brasil. O uso das tic como ferramenta de ensino da histologia nos cursos de odontologia das regiões sul e sudeste do brasil. Revista iberoamericana de tecnología en educación y educación en tecnología, v. 22, n. 22, p. 63-72, 2018. doi: 10.24215/18509959.22.e07

REIS, C.; MARTINS, M.M.; MENDES, M.R.A.F.; GONÇALVES, L.B.; FILHO, S.C.H.; MORAIS, M.R.; OLIVERIRA, S.E.B.; GIMARÃES, A.L.S. Avaliação da Percepção de Discentes do Curso Médico acerca do Estudo Anatômico. Revista brasileira de educação médica, v. 37, n. 3, p. 350-358, 2013. doi: https://doi.org/10.1590/S010055022013000300007

SANTA-ROSA, J.G.; STRUCHINER, M. Tecnologia Educacional no Contexto do Ensino de Histologia: Pesquisa e Desenvolvimento de um Ambiente Virtual de Ensino e Aprendizagem. Revista Brasileira de Educação Médica, v. 35, n. 2, p. 289-298, 2011. Doi: 10.1590/S010055022011000200020

SCHNEIDER, H.N.; SOUZA, A.A.N. Potencialidades do uso de sites de redes sociais no processo de ensino e aprendizagem. International Journal of Knowledge Engineering and Management, v. 3, n. 6, p. 181-196, 2014. Disponível em: < http://incubadora.periodicos.ufsc.br/index.php/IJKEM/article/view/2747/3476>

SILVA, F.S.; SERAFIM, M.L. Redes Sociais no Processo de Ensino e Aprendizagem: com a palavra o adolescente. IN: SOUSA, R.P.; BEZERRA, C.C.; FILOMENA, E.M.S.; MOITA, M.G.S. Teorias e práticas em tecnologias educacionais (ONLINE). Campina Grande: EDUEPB, 2016, 228 p. Disponível em: http://books.scielo.org/id/fp86k/pdf/sousa-9788578793265.pdf - Acesso em $23 / 01 / 2019$

SCHERER, A.L.; FARIAS, J.G. Uso da Rede Social Facebook como Ferramenta de Ensino-aprendizagem em Cursos de Ensino Superior. Revista Brasileira de Aprendizagem Aberta e a Distância, v. 1, p. e44, 2018. doi:

10.17143/rbaad.v17i1.44

TORI, R. Educação sem distancia - As tecnologias interativas na redução de distancias em ensino e aprendizagem. $2^{\underline{a}}$ ed, ed. Artesanato Educacional, São Paulo, 254p. 2017.

VALENTE, J.A. A Comunicação e a Educação baseada no uso das Tecnologias Digitais de Informação e Comunicação. Revista UNIFESO - Humanas e Sociais, v. $1, \quad$ n. 1, p. 141-166, 2014. Disponível em: < http://www.revista.unifeso.edu.br/index.php/revistaunifesohumanasesociais/article/vi ew/17>

VASCONCELOS, D.F.P.; VASCONCELOS, A.C.C.G. Desenvolvimento de um Ambiente Virtual de Ensino em Histologia para Estudantes da Saúde. Revista brasileira de educação médica, v. 37, n. 1, p. 132-137, 2013. doi: 10.1590/S010055022013000100019. 
ZUINS, A. A.S. A cultura digital, o professor-criança e o aluno-adulto. Revista de educação pública, v. 25 , n. $29 / 1$, p. $329-339$, 2016. Disponível em: < http://periodicoscientificos.ufmt.br/ojs/index.php/educacaopublica/article/view/3678> 